\title{
ARE THERE LONG TERM PROTECTIVE EFFECTS OF BREAST FEEDING AGAINST LATER OBESITY?
}

\author{
BERTHOLD KOLETZKO AND *RÜDIGER VON KRIES
}

Department of Pediatrics, Dr. von Haunersches Kinderspital, and *Institute for Social Pediatrics and Adolescent Medicine, Ludwig-Maximilians-University of Munich, Germany

Obesity is now considered a global epidemic because its prevalence in both adults children is increasing worldwide at an alarming rate. ${ }^{1-7}$ This increase is occurring not only in affluent countries but also in countries in economic transition and in developing countries. It has been related to an increasingly sedentary lifestyle with less physical activity, as well as to changing dietary habits. ${ }^{6,8-11}$ Obesity has marked adverse effects in childhood and adolescence as well as long term effects that extend well into adulthood. Obese children often experience psychosocial distress and, in many cultures, considerable discrimination. Obese adolescents are at a clear disadvantage with respect to completion of advanced education, household income achieved in adulthood, and rates of marriage. ${ }^{12,13}$ Obesity during childhood and adolescence affects the cardiovascular risk factors of dyslipidemia, glucose intolerance, and arterial hypertension.

Dyslipidemia, with increased concentrations of plasma triglycerides and low density lipoprotein cholesterol and reduced high density lipoprotein cholesterol, is a common finding in young obese individuals. ${ }^{14,15}$ Obesity causes reduced insulin sensitivity, pathological glucose tolerance, and increased fasting and postprandial blood glucose concentrations, and it appears to play a key role in the marked increase of non-insulin-dependent diabetes mellitus recently observed in some pediatric populations. ${ }^{16}$

Other consequences of early obesity are non-alcoholic steatohepatitis, which is not always benign but may result in cirrhosis, ${ }^{17,18}$ cholelithiasis, pseudotumor cerebri, sleep apnea (which may be associated with neurocognitive deficits), disorders of the musculoskeletal system, and orthopedic complications with an increased long term risk of arthrosis, as well as polycystic ovary disease. ${ }^{15}$

Persistence of childhood obesity into adult life is common. It has been estimated that between one third and two thirds of all obese children become obese adults, whereas about one third of adult obesity develops from obesity 
already manifest in childhood. ${ }^{19,20}$ The risk of persistent obesity increases with increasing age of the child, the degree of obesity, and the presence of parental obesity. ${ }^{21}$ Persistence of obesity during adult life is associated with markedly increased morbidity and mortality. ${ }^{22,}{ }^{23}$ It is of interest that childhood obesity is also reported to be related to an increased morbidity risk in adulthood even if obesity does not persist into adult life. ${ }^{24,25}$

In view of these marked adverse effects of childhood obesity, the fight against this new epidemic has become a prime objective for pediatric health care. ${ }^{1,2,26}$ As available therapeutic interventions in obese children aiming at weight loss are costly and have less than satisfactory long term success rates, identification of strategies for effective prevention of obesity is particularly attractive.

\section{EARLY METABOLIC IMPRINTING}

Although genetic predisposition is of major importance for an individual's risk of becoming obese, ${ }^{27,28}$ the rapid increase in obesity prevalence in many parts of the world provides evidence for the strong modulating effects of exogenous factors. In addition to current lifestyle factors, events during early life appear to modulate later obesity risk, a phenomenon referred to as metabolic programming ${ }^{29}$ or metabolic imprinting. ${ }^{30}$

Indications for the existence of metabolic imprinting of obesity were provided by Ravelli and coworkers, who studied a cohort study of 19-year-old men at military induction who had been exposed during perinatal life to the Dutch famine of 1944-45. ${ }^{31}$ In this cohort, maternal exposure to famine during the last trimester of pregnancy and the first months of life was related to significantly lower obesity rates, while exposure during the first half of pregnancy resulted in a higher obesity prevalence than in non-exposed controls. ${ }^{31} \mathrm{~A}$ later follow up study of women and men at age 50 years who were either exposed or not exposed to famine in late, mid, or early gestation reported a significantly higher body mass index (BMI) in exposed than nonexposed women, whereas there was no significant difference in men. ${ }^{32}$ Also, children of Pima women with diabetes during pregnancy were found to have a higher risk of later obesity than children of mothers who did not suffer from gestational diabetes, which persisted after correction for other influencing factors. ${ }^{33}$ The findings cited suggest that metabolic perturbations of regulatory systems established in early gestation contribute to the development of obesity in later life.

In view of these results, we have recently addressed the question of whether prolonged breast feeding might have long term programming effects on the prevalence of overweight and obesity in children at school entry ${ }^{34}$ In this study-carried out in the state of Bavaria, Germany - the risk for overweight and obesity was decreased by exclusive breast feeding. Here we aim to summarize the results of that study, discuss whether the apparently reduced risk 
for overweight and obesity in breast-fed children can be attributed to the properties of human milk, give further details on the lower prevalence of overweight/obesity in breast-fed children in Bavaria, and stimulate discussion as to which components of human milk might be instrumental in reducing the risk of obesity in breastfed children

\section{STUDY DESIGN AND SETTING}

The study was performed as part of the Bavarian school entry health examinations 1997 enrolling 134,577 children (Fig. 1). From February 1997 to August 1997 some 13,345 children examined in two rural Bavarian regions (Oberpfalz and Niederbayern) and their parents were given a questionnaire on risk factors for atopic diseases. The overall response rate by the parents was $76.2 \%$. The total number of completed questionnaires was 10,163 . These data were linked to data on length and weight, measured as part of the routine health examination. The BMI was calculated as weight $(\mathrm{kg}) / \mathrm{height}^{2}(\mathrm{~m})$. The analysis was confined to 5 year old $(\mathrm{n}=1975)$ and 6 year old $(\mathrm{n}=7382)$ German children, resulting in 9357 questionnaires for the analyses. The age and sex specific distribution of the BMI in all German children investigated during the 1997 school health examination in Bavaria was used as the reference to define overweight (BMI $>90$ th centile) and obesity (BMI $>97$ th centile).

The main exposure was exclusive breast feeding and its duration. The question on breast feeding was: "Was your child breast-fed?" If the answer was yes, the further question was: "For how long was your child exclusively breast-fed?" The categories offered in answering this question were: for not more than 2 months; 3 to 5 months; 6 to 12 months; and for more than a year.

In order to identify covariables potentially associated with breast feeding, several additional items were considered. These included housing characteristics and lifestyle (for example, the age of the house, whether the child had a separate bedroom, maternal smoking in pregnancy, spare time spent outside in summer and winter), questions on the child's health (prematurity, low birthweight), questions on diet (time of introduction of solid foods, consumption of own cooked food or industrial ready-to-feed products, food bought in health food shops), and quantitative questions (never, less than once weekly, once or twice, three to six times weekly, or daily) on the consumption of selected dietary items (milk products, fish, meat, fat, carbohydrates). The highest education of either parent was used as a marker of social class.

\section{MAIN RESULTS}

The duration of breast feeding was associated with a progressive reduction in the prevalence of overweight - and even more so of obesity-in children at 
Participated in school health examination - length and weight measured

$n=134,577$

Children in 2 rural regions, who received additional questionaire

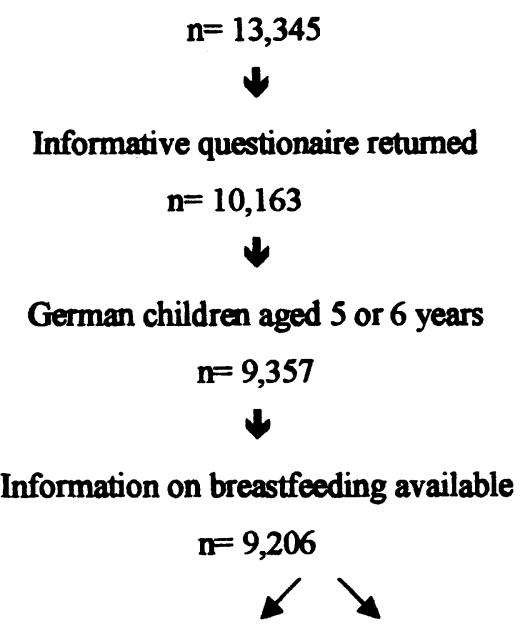

Never breastfed, $n=4,022$

Ever breastfed, $n=5,184$

Figure 1. Schematic depiction of the study population derived from the obligatory school health examination in Bavaria in 1997.

school entry (Fig. 2). Previously breast-fed and non-breast-fed children differed significantly in several indicators of social class and lifestyle. Many of these were also associated with overweight or obesity. High parental education, prematurity, and low birthweight were associated with a reduced risk of overweight and obesity, whereas maternal smoking during pregnancy was related to an increased risk. Full fat milk products (milk, quark or yogurt, whipped cream) and sweet deserts may be avoided by overweight children, suggesting a spurious "protective" effect of these products as compared to a "risk" associated with the consumption of the low fat version of these products. There was also an apparent reduction of the risk of overweight and obesity associated with a high consumption of butter and breakfast cereals. ${ }^{34}$

Parental education was the only factor accounting for a $>10 \%$ shift of the odds ratio for breast feeding and overweight and obesity towards unity. Other factors which remained significantly associated with overweight/obesity in the 


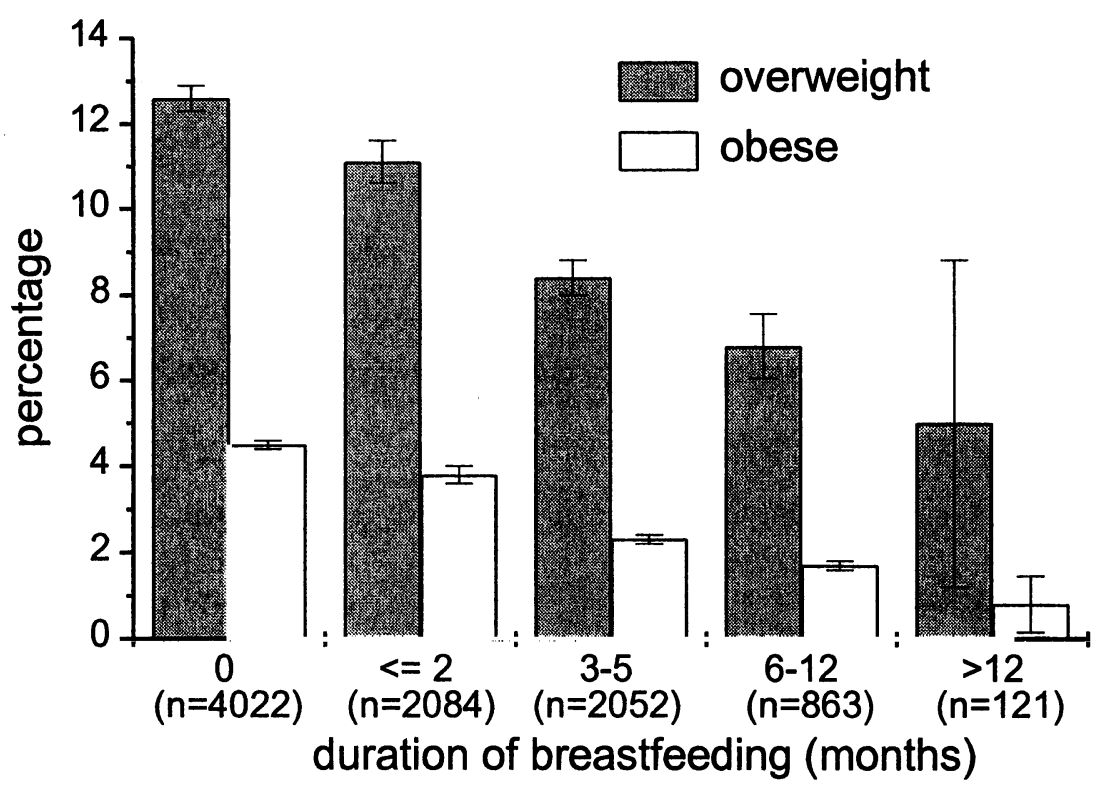

Figure 2. Relation of breast-feeding after birth to overweight (BMI $>90$ th centile) and obesity (BMI > 97th centile). Prevalence in German children aged 5 or 6 years.

final logistic regression model were high parental education, maternal smoking during pregnancy, low birthweight, having a separate bedroom for the child, and frequent consumption of butter (Table 1). The adjusted odds ratios by duration of breast feeding are shown in Fig. 3. Being ever breast-fed reduced the risk of overweight by more than 20\%, and breast feeding for 6 months or more reduced the risk by over $35 \%$. Even more pronounced effects were observed with respect to obesity ( $25 \%$ and $43 \%$, respectively).

\section{IS THE REDUCED RISK FOR OVERWEIGHT AND OBESITY IN BREAST-FED CHILDREN RELATED TO PROPERTIES OF HUMAN MILK?}

With all cross sectional studies there is a risk of recall/information bias. Some misclassification of the duration of breast feeding is likely when mothers have to remember details of their child's earlier feeding. This misclassification, however, is unlikely to be related to the outcome, because the overt aim of the study was the search for risk factors of atopic disease. Selection bias is also unlikely - the return rate of the questionnaires was high and unrelated to the outcome measure ${ }^{34}$ Random misclassification of the measurement of height and weight is probable, as it is difficult to ensure that all persons involved in the measurement in more than 10 different public health offices used exactly 
TABLE 1

Factors associated with breast-feeding and overweight and obesity in 5 or 6 year old German children and their impact on overweight and obesity (only significant factors in a logistic regression model with breast-feeding included)

\begin{tabular}{|c|c|c|c|c|c|c|}
\hline & \multicolumn{2}{|c|}{ Prevalence in } & \multicolumn{2}{|c|}{ Overweight } & \multicolumn{2}{|c|}{ Obesity } \\
\hline & $\begin{array}{c}\text { Not breast- } \\
\text { fed Children } \\
\%\end{array}$ & $\begin{array}{l}\text { Breast-fed } \\
\text { Children } \\
\%\end{array}$ & OR & $90 \%$ & OR & $90 \% \mathrm{Cl}$ \\
\hline $\begin{array}{l}\text { high parental education* } \\
\text { Maternal smoking }\end{array}$ & 41.4 & 66.7 & 0.77 & $0.6-0.89$ & 0.62 & $0.49-0.79$ \\
\hline in pregnancy & 12.8 & 4.2 & 1.51 & $1.20-1.89$ & 1.82 & $1.28-2.58$ \\
\hline Prematurity & 13.8 & 9.0 & 0.78 & $0.62-0.98$ & .69 & $0.46-1.03$ \\
\hline Birthweight $<2500 \mathrm{~g}$ & 10.4 & 6.6 & 0.69 & $0.48-0.84$ & 0.78 & $0.54-1.10$ \\
\hline Own bedroom & 45.6 & 54.4 & 1.19 & $1.03-1.37$ & 1.22 & $0.96-1.56$ \\
\hline $\begin{array}{l}\text { Margarine }>=3 \\
\text { times per week }\end{array}$ & 35.3 & 32.4 & 1.22 & $1.05-1.41$ & 1.21 & $0.94-1.56$ \\
\hline $\begin{array}{l}\text { Butter }>=3 \\
\text { times per week } \\
\text { Full fat milk }>=3\end{array}$ & 60.5 & 69.2 & 0.73 & $0.63-0.83$ & 0.70 & $0.56-0.88$ \\
\hline $\begin{array}{c}\text { times per week } \\
\text { Low fat milk }>=3\end{array}$ & 50.8 & 59.6 & 0.69 & $0.60-0.80$ & 0.54 & $0.42-0.68$ \\
\hline $\begin{array}{l}\text { times per week } \\
\text { Full fat quark or yogurt }\end{array}$ & 31.9 & 28.8 & 1.72 & $1.49-1.99$ & 1.77 & $1.38-2.25$ \\
\hline $\begin{array}{c}>=3 \text { times per week } \\
\text { Low fat quark or yogurt }\end{array}$ & 28.8 & 36.1 & 0.66 & $0.56-0.78$ & 0.52 & $0.38-0.70$ \\
\hline $\begin{array}{c}>=3 \text { times per week } \\
\text { Whipped cream }>=\text { once }\end{array}$ & 25.9 & .8 & 1.42 & $1.22-1.66$ & 1.32 & $1.02-1.71$ \\
\hline $\begin{array}{l}\text { per week } \\
\text { Breakfast cereals }>=3\end{array}$ & 18.6 & 24.7 & 0.65 & $0.54-0.79$ & 0.58 & $0.41-0.81$ \\
\hline $\begin{array}{c}\text { times per week } \\
\text { Sweet deserts }>=3\end{array}$ & 25.6 & 35.3 & 0.80 & $0.68-0.93$ & 0.76 & $0.58-0.99$ \\
\hline times per week & 54.4 & 57.8 & 0.84 & $0.74-0.97$ & 0.82 & $0.66-1.03$ \\
\hline
\end{tabular}

*at least $10 \%$ change of the OR for breast-feeding and overweight/obesity

the same equipment in exactly the same way. This misclassification, however, is unlikely to be dependent on breast feeding, as that information was not known to the persons involved in the measurement.

Breast feeding was associated with various lifestyle and dietary factors documented as part of the study. With the exception of parental education, none of these was a confounder of the association of breast feeding and overweight/obesity. High parental education in breast-fed children, however, only partially explained the association of breast feeding and overweight/ obesity.

Information on important risk factors for overweight which might be confounders of the presumed protection by breast feeding could not be assessed optimally. These included lifestyle/social class and genetic risk factors for overweight or obesity. 


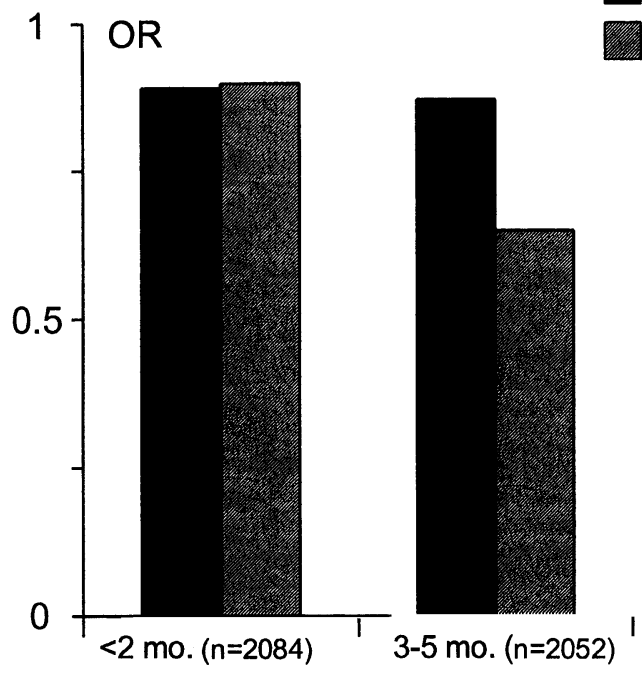

Overweight (BMI>90th perc.) Obesity (BMI>97th perc.)

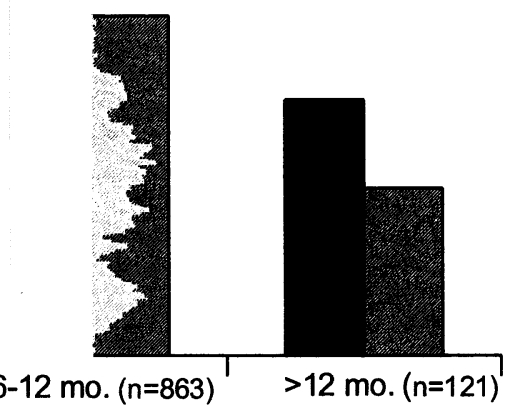

Figure 3. Impact of the duration of breast feeding on odds ratio for overweight and obesity in German children aged 5 or 6 . Odds ratios are adjusted for parental education, maternal smoking in pregnancy, low birthweight, own bedroom, and frequent consumption of butter.

\section{Lifestyle and Social Class}

Parental education may not be the optimal indicator of social class, but additional information is difficult to obtain in Germany because a potential impact of social class on health is not perceived by the German population.

Physical activity is certainly an important risk factor for overweight/ obesity. As the questionnaire had not been originally designed for this purpose these questions were limited to "time for playing outdoors", which-though associated with breast feeding-was not associated with overweight/obesity and was not a confounding variable.

Diet is another important lifestyle factor associated with the risk of adiposity. The questions on this were confined to a semi-quantitative assessment of the present diet. Many overweight children, however, might have changed diet to reduce their weight.

\section{Genetic Risk Factors for Overweight/Obesity}

Parents' weight is an important indicator of the genetic risk for overweight/ obesity, ${ }^{27,28}$ and maternal overweight appears to be associated with a short duration of breast feeding or no breast feeding. ${ }^{35}$ A positive family history of adiposity was not a confounder of the association between breast feeding and overweight/obesity in a previous study. ${ }^{36}$ After the publication of our results, 
the issue was investigated in another prospective cohort study, the German multicenter allergy study (MAS). ${ }^{37,38}$ In the MAS cohort, longer breast feeding was less common in overweight mothers, but maternal overweight was not a confounder of the association of breast feeding and overweight/ obesity.

A strong argument against lifestyle factors explaining the observed protective effect of breast feeding comes from a study by Kramer on Canadian adolescents born in the 1960s. ${ }^{36}$ In that study a similar dose-related, protective effect of breast feeding on the later prevalence of overweight/obesity was found. If such a dose-dependent protective effect were caused by lifestyle factors associated with breast feeding, similar confounding factors should have to have been operative during the different time periods in different societies. In Kramer's study only $18.5 \%$ of the children had been breast-fed, compared with 56\% our study, suggesting that the mothers who chose to breast feed their children in the 90s in Bavaria formed a different population from those who chose to breast feed in the 60s in Canada. The lifestyle in the early 60s in Canada was almost certainly different from that in Bavaria in the early 90s. Although it is difficult to rule out the possibility that unknown factors associated with the lifestyle of families of breast-fed children might play a causative role in the apparent protective effect of breast feeding, this does not appear likely.

\section{BODY MASS INDEX OF THE CHILDREN STUDIED}

The age and sex specific distribution of the BMI in all German children investigated during the 1997 school health examination in Bavaria was used as the reference to define overweight (BMI > 90th centile) and obesity (BMI $>97$ th centile). The 90th and 97th centiles in Bavaria are considerably higher than the widely used French reference values ${ }^{39}$ (Table 2). Thus most children defined as overweight according to the Bavarian centiles would have BMI values above the 95th centile of the French reference values.

The lower prevalence of overweight/obesity in breast-fed children in Bavaria does not reflect a shift in the entire distribution of the BMIs in breastfed children as compared with formula-fed children. There is no shift of the mean but the upper tail of the distribution is "fatter" in non-breast-fed children (Fig. 4). This has implications for other studies in that our findings might not be reproduced if only means and their 95\% confidence intervals are considered. The biological model to explain the observed protective effect on overweight and obesity should match a shift in the "upper tail".

As our study was cross sectional, we do not have data on the longitudinal evolution of BMI during the first 5 years of life in these children. However, such longitudinal data are available from the analysis of the prospective German MAS study. ${ }^{37,38}$ It is of interest that the BMI data from the MAS cohort show that differences between the subgroups which had been breast-fed 
TABLE 2

Prevalence (95\% $\mathrm{Cl}$ in brackets) of overweight (BMI > 90th percentile) and obesity (BMI > 97th percentile) in German children aged 5 or 6 living in two rural Bavarian regions in relation to breast-feeding.

\begin{tabular}{llcc}
\hline & & $\begin{array}{c}\text { Overweight } \\
\%\end{array}$ & $\begin{array}{c}\text { Obesity } \\
\%\end{array}$ \\
\hline Never breast-fed & $(\mathrm{n}=4,022)$ & 12.63 & 4.48 \\
& & $(12.36-12.90)$ & $(4.38-4.58)$ \\
Ever breast-fed & $(\mathrm{n}=5,184)$ & 9.18 & 2.78 \\
& & $(9.02-9.34)$ & $(2.73-2.83)$ \\
Breast-fed for: & & 11.13 & 3.79 \\
$<2$ months & $(\mathrm{n}=2,084)$ & $(10.60-11.59)$ & $(3.62-3.96)$ \\
$3-5$ months & $(\mathrm{n}=2,052)$ & 8.43 & 2.29 \\
& & $(8.06-8.80)$ & $(2.18-2.40)$ \\
$6-12$ months & $(\mathrm{n}=863)$ & 6.84 & 1.74 \\
& & $(6.12-7.56)$ & $(1.55-1.93)$ \\
$>12$ months & $(\mathrm{n}=121)$ & 4.96 & 0.83 \\
& & $(1.14-8.78)$ & $(0.16-1.50)$ \\
\hline
\end{tabular}

for less than 2 months or for at least 2 months, respectively, only evolved after the fourth year of life - that is, at the time of BMI rebound. ${ }^{38}$ Thus other studies that observe children aged less than 5 years might not be able to detect any BMI differences related to postnatal feeding.

\section{ARE THERE COMPONENTS IN HUMAN MILK THAT REDUCE THE RISK OF OBESITY IN BREAST-FED CHILDREN?}

Features of human milk feeding that might account for a lower risk for overweight/obesity in breast-fed infants could include hormonal responses, bioactive factors in the milk, a lower energy intake, or a lower protein intake, all of which might have long term effects.

Lucas et al. ${ }^{40,41}$ reported significantly higher plasma insulin concentrations in formula-fed than in breast-fed infants, which would be expected to stimulate fat deposition and thus affect the early development of adipocytes. Human milk also contains bioactive factors that may modulate tissue growth and development. Breast milk contains both epidermal growth factor and tumor necrosis factor $\alpha$, both of which are known to inhibit adipocyte differentiation in vitro. ${ }^{34}$

Nutrient intakes of breast-fed and formula-fed infants differ. Recent data indicate that the metabolizable energy and protein intakes of breast-fed infants are considerably lower than previously assumed and significantly below those found in populations of formulated infants. ${ }^{34}$ These early differences in macronutrient supply might have long term effects on substrate metabolism. 


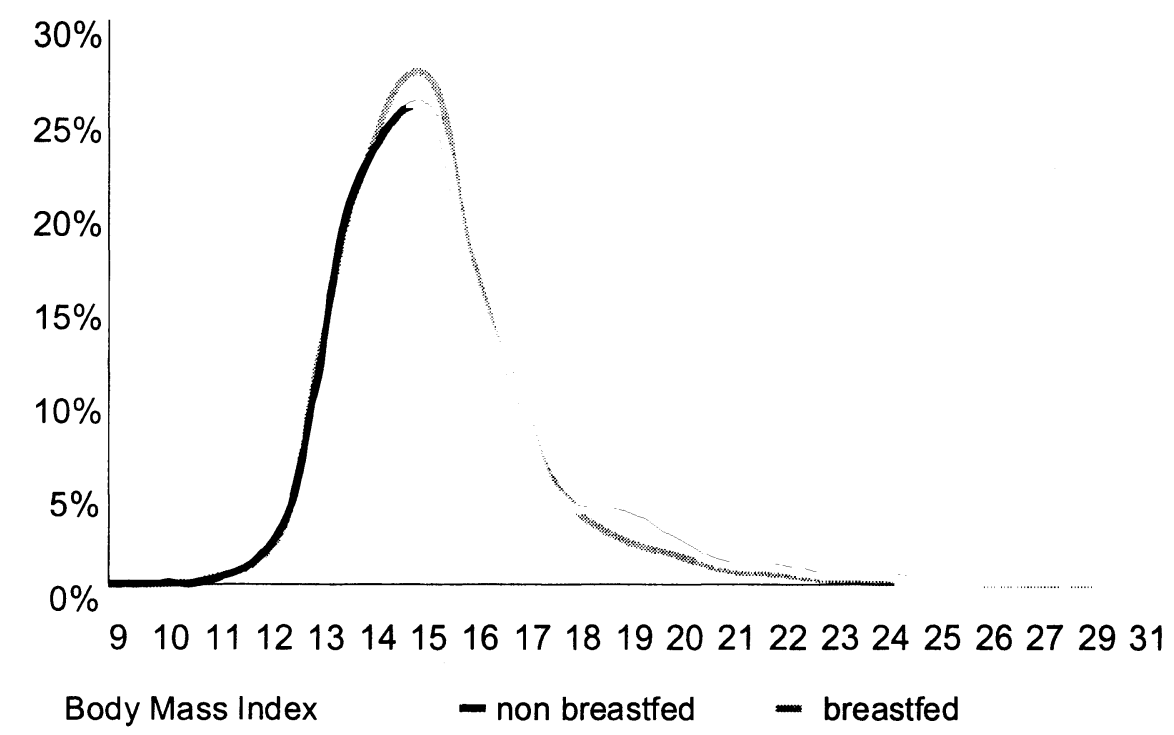

Figure 4. BMI distribution in breast-fed and non-breast-fed German children aged 5 and 6 years.

In longitudinal follow up studies, Rolland-Cachera and coworkers observed a significant relation between the dietary protein intake at the age of 10 months with later BMI and body fat distribution. ${ }^{42,43}$ These investigators proposed that a high protein intake in early childhood might predispose to an increased risk of obesity at a later age. Indeed, in animal studies the early protein availability during fetal and postnatal development was found have long term metabolic programming effects on glucose metabolism and body composition in adult life. Whether or not postnatal intake of protein or other substrates does indeed affect later body composition needs to be tested in properly designed prospective trials.

\section{CONCLUSIONS}

Based on the data from this cross sectional study enrolling almost 10,000 children, there is strong evidence that breast-fed children are less likely to be overweight or obese at school entry than formula-fed children. This effect reflects "fattening" of the upper tail of the BMI distribution for non-breast-fed children but is not caused by a shift of the mean BMI.

There are some indications that the reduced risk of overweight/obesity in breast-fed children might be related to properties of human milk and not to different genetic or lifestyle factors in these children. However, at present we cannot exclude the possibility that confounding variables such as parental 
BMI or other factors associated with breast feeding might play a role. Further research is needed to elucidate the causal factors.

\section{REFERENCES}

1. World Health Organisation. Obesity. Preventing and managing the global epidemic. Report of a WHO consultation on obesity. Geneva: World Health Organisation, 1998.

2. Koletzko, B., Chen, W., Girardet, J.P., Klish, W., Leung, S., Tabacco, O. (1998). Obesity in children and adolescents worldwide: current views and future directions. J Pediatr Gastroenterol Nutr, in press.

3. Troiano, R.P. and Flegal, K.M. (1998). Overweight children and adolescents: description, epidemiology, and demographics. Pediatrics, 101, 497-504.

4. Kopelman, P.G. (2000). Obesity as a medical problem. Nature, 404, 635-43.

5. Cernerud, L. (1993). Height and body mass index of seven-year-old Stockholm schoolchildren from 1940 to 1990. Acta Paediatr, 82, 304-5.

6. Popkin, B.M. and Doak, C.M. (1998). The obesity epidemic is a worldwide phenomenon. Nutr Rev, 56, 106-14.

7. Freedman, D.S., Srinivasan, S.R., Valdez, R.A., Williamson, D.F. and Berenson, G.S. (1997). Secular increases in relative weight and adiposity among children over two decades: the Bogalusa Heart Study. Pediatrics, 99, 420-6.

8. Popkin, B.M. (1998). The nutrition transition and its health implications in lower-income countries. Public Health Nutr, 1, 5-21.

9. Drewnowski, A. and Popkin, B.M. (1997). The nutrition transitions new trends in the global diet. Nutr Rev, 55, 31-43.

10. Schroeder, D.G., Martorell, R. and Flores, R. (1999). Infant and child growth and fatness and fat distribution in Guatemalan adults. Am J Epidemiol, 149, 177-85.

11. Martorell, R., Khan, L.K., Hughes, M.L. and Grummer, S.L. (1993). Obesity in women from developing countries. Eur J Clin Nutr, 54, 247-52.

12. Gortmaker, S.L., Must, A., Perrin, J.M., Sobol, A.M. and Dietz, W.H. (1993). Social and economic consequences of overweight in adolescence and young adulthood [see comments]. $N$ Engl J Med, 329, 1008-12.

13. Sargent, J.D. and Blanchflower, D.G. (1994). Obesity and stature in adolescence and earnings in young adulthood. Analysis of a British birth cohort [see comments]. Arch Pediatr Adolesc Med, 148, 681-7.

14. Vanhala, M., Vanhala, P., Kumpusalo, E., Halonen, P. and Takala, J. (1998). Relation between obesity from childhood to adulthood and the metabolic syndrome: population based study. BMJ, 317, 319.

15. Dietz, W.H. (1998). Health consequences of obesity in youth: childhood predictors of adult disease. Pediatrics, 101, 518-25.

16. Pinhas, H.O., Dolan, L.M., Daniels, S.R., Standiford, D., Khoury, P.R. and Zeitler, P. (1996). Increased incidence of non-insulin-dependent diabetes mellitus among adolescents. J Pediatr, 128, 608-15.

17. Rashid, M. and Roberts, E.A. (2000). Nonalcoholic steatohepatitis in children. J Pediatr Gastroenterol Nutr, 30, 48-53.

18. Kinugasa, A., Tsunamoto, K., Furukawa, N., Sawada, T., Kusunoki, T. and Shimada, N. (1984). Fatty liver and its fibrous changes found in simple obesity of children. $J$ Pediatr Gastroenterol Nutr, 3, 408-14.

19. Serdula, M.K., Ivery, D., Coates, R.J., Freedman, D.S., Williamson, D.F. and Byers, T. (1993). Do obese children become obese adults? A review of the literature. Prev Med, 22, 167-77.

20. Power, C., Lake, J.K. and Cole, T.J. (1997). Body mass index and height from childhood to adulthood in the 1958 British born cohort. Am J Clin Nutr, 66, 1094-101. 
21. He, Q. and Karlberg, J. (1999). Prediction of adult overweight during the pediatric years. Pediatr Res, 46, 697-703.

22. Blair, S.N. and Brodney, S. (1999). Effects of physical inactivity and obesity on morbidity and mortality: current evidence and research issues. Med Sci Sports Exerc, 31(suppl), S646-62.

23. Jung, R.T. (1997). Obesity as a disease. Br Med Bull, 53, 307-21.

24. Must, A., Jacques, P.F., Dallal, G.E., Bajema, C.J. and Dietz, W.H. (1992). Long-term morbidity and mortality of overweight adolescents. A follow-up of the Harvard Growth Study of 1922 to 1935 [see comments]. $N$ Engl J Med, 327, 1350-5.

25. Gunnell, D.J., Frankel, S.J., Nanchahal, K., Peters, T.J. and Davey, S.G. (1998). Childhood obesity and adult cardiovascular mortality: a 57-y follow-up study based on the Boyd Orr cohort. Am J Clin Nutr, 67, 1111-18.

26. Rosenbaum, M., Leibel, R.L. and Hirsch, J. (1986). Obesity. N Engl J Med, 337, 396-407.

27. Stunkard, A.J., Sorensen, T.I., Hanis, C. et al. (1986). An adoption study of human obesity. $N$ Engl J Med, 314, 193-8.

28. Barsh, G.S., Farooqi, I.S. and O'Rahilly, S. (2000). Genetics of body-weight regulation. Nature, 404, 644-51.

29. Barker, D.J. (1998). In utero programming of chronic disease. Clin Sci, 95, 115-28.

30. Waterland, R.A. and Garza, C. (1999). Potential mechanisms of metabolic imprinting that lead to chronic disease. Am J Clin Nutr, 69, 179-97.

31. Ravelli, G.P., Stein, Z.A. and Susser, M.W. (1976). Obesity in young men after famine exposure in utero and early infancy. $N$ Engl $J$ Med, 295, 349-53.

32. Ravelli, A.C., van-Der, M.J., Osmond, C., Barker, D.J. and Bleker, O.P. (1999). Obesity at the age of $50 \mathrm{y}$ in men and women exposed to famine prenatally. Am J Clin Nutr, 70, 811-16.

33. Pettitt, D.J., Baird, H.R., Aleck, K.A., Bennett P.H. and Knowler, W.C. (1983). Excessive obesity in offspring of Pima Indian women with diabetes during pregnancy. $N$ Engl J Med, 308, 242-5.

34. von Kries, R., Koletzko, B., Sauerwald, T., Barnert, D. and Grunert, V. (1999). Breast feeding and obesity: cross sectional study. $B M J, 319,147-50$.

35. Hilson, J.A., Rasmussen, K.M. and Kjolhede, C.L. (1997). Maternal obesity and breastfeeding success in a rural population of white women. Am J Clin Nutr, 66, 1371-8. [Published erratum appears in Am J Clin Nutr, 1998, 67, 494.]

36. Kramer, M.S. (1981). Do breast-feeding and delayed introduction of solid foods protect against subsequent obesity? $J$ Pediatr, 98, 883-7.

37. Kulig, M., Bergmann, R., Edenharter, G. and Wahn, U. (2000). Does allergy in parents depend on allergy in their children? Recall bias in parental questioning of atopic diseases. Multicenter Allergy Study Group. J Allergy Clin Immunol, 105, 274-8.

38. Bergmann, K.E., Bergmann, R.L., von Kries, R. et al. (2000). Beugt Stillen der Adipositas'? (Does breast-feeding prevent obesity?). [Abstract] Klin Pädiatr, 212, S75.

39. Rolland, C.M., Cole, T.J., Sempe, M., Tichet, J., Rossignol, C. and Charraud, A. (1991). Body mass index variations: centiles from birth to 87 years. Eur J Clin Nutr, 45, 13-21.

40. Lucas, A., Boyes, S., Bloom, S.R. and Aynsley, G.A. (1981). Metabolic and endocrine responses to a milk feed in six-day-old term infants: differences between breast and cow's milk formula feeding. Acta Paediatr Scand, 70, 195-200.

41. Lucas, A., Sarson, D.L., Blackburn, A.M., Adrian, T.E., Aynsley, G.A. and Bloom, S.R. (1980). Breast vs bottle: endocrine responses are different with formula feeding. Lancet, i, 1267-9.

42. Parizkova, J. and Rolland, C.M. (1997). High proteins early in life as a predisposition for later obesity and further health risks [editorial]. Nutrition, 13, 818-19.

43. Rolland, C.M., Deheeger, M., Akrout, M. and Bellisle, F. (1995). Influence of macronutrients on adiposity development: a follow up study of nutrition and growth from 10 months to 8 years of age. Int J Obes Relat Metab Disord, 19, 573-8. 